\title{
Alternatives Formation of Bricks Pattern from Trowulan through Parametric Design
}

\author{
Stephanus Evert Indrawan \\ Interior Architecture Department, Ciputra University \\ UC Town-Citraland Surabaya \\ sindrawan@ciputra.ac.id \\ Tri Noviyanto P. Utomo \\ Interior Architecture Department, Ciputra University \\ UC Town-Citraland Surabaya \\ tommy@ciputra.ac.id
}

\begin{abstract}
This research is a continuation of the potential mapping from Trowulan Art and Crafts commodity based on its material which consist of Terracotta, Stone and Brass. Studies are limited to Terracotta and bricks as its products. Terracotta of Trowulan has a distinctive color texture and the product that based on this material are mostly sculpture, roofs tile, roofs ornament and bricks. Bricks are the most common material for building construction and being exposed in a common principles of bricks formation. This recent research aims to find an alternative principles of bricks formation through parametric design approach. The software that being used are Rhinoceros and Grasshopper plug ins. Product of studies are parametric script that enables designer to make a well calculated simulation and shorten the prototyping process. It is also implemented as design module or designs pattern that can be developed manually by handworkers.
\end{abstract}

Keywords: parametrics, designs pattern, products design, terracotta

\section{INTRODUCTION}

Trowulan district located in Mojokerto (East Java). Trowulan established around 1900. There are many artifacts and historic site that has been discovered and it gives an information about Trowulans ancient cultures and the Empire of Majapahit. Beside of its historic value as Majapahit Legacies, Trowulan also known as a place for handicraft. There are a cluster of artist that spread in different area that categorize based on 3 main material used which is terracota, stone and bronze. The category based on the facts that the majority of Majapahits artifacts that has been discovered was made out of these 3 materials.(Utomo et al. n.d.)

Based on Indonesian archeology definition, terracotta is a clay that has been through burning process. Among Terracota products there are form of figurine (both human and animal), temple models, traditional house models or detail of traditional house. Terracota products supports the economy of villagers. Beside 
of handicraft, bricks also a featured product from this district.Traditional bricks process, form and application still untouched by modern technology and design method. The bricksprocess are strongly depend on weather situation, form that was used mostly 240x115x52 (LxWxD)(Akmal 2010) in a box shaped and the application are mostly for buildings wall.Bricklaying formations still follow traditional formations or follow the standard construction of conventional bricks but its tectonics quality shows an image of Majapahit culture. Bricks of Trowulan has a typical red color of Majapahit Temple. Nowadays, the situation of bricks industry in the last few years was not going well. Traditional bricks have to compete with light bricks which produced by modern industry. The price was more affordable, not labour intensive and its not depend on weather situation. Younger generation tend to leave this business and choose to work in the cities or working in different industries. Based on this situation this research is focusing on the application process in order to preserve and re-adding value of local skills and material. The aim of research are involving the digital generative designs tools to bricklayering process without reducing the role of handworkers.

\section{TECTONICS: GROUND THEORIES}

Digital Technology development makes more possibilities to apply an interrelationship between technology and design. The combination of digital design and manufacturing technologies are shifting material-related design studies and practices. There are two types of model practices as stated by Sheila Kennedy (Kennedy, 2011). First, the horizontal model is a design based model that need a well-understood design models and knowledge. It is a traditional way of model. Secondly, the vertical model that underlining synthesis of new techniques, experimental models of design and embedded technologies. The concept of tectonics will be explained as reported by Rivka Oxman (Oxman, 2012).

Tectonics based of Historical refrences. Tectonics word or Tekton originaly from Greek word that means carpenter or builder. Tectonics is a concept that defines the relationship between architectural design and its structures and materials. The relationship between Architectures and structures was changing from time to time influenced by its periods (R. Oxman, 2010). There are concept of tectonics that defines its relation to informed tectonics.

1. Vernacular Tectonics was the origin of tectonics expression. Vernacular design always expressing the essence of material technology. In the Vernacular traditional material technologies evolve to become buildings system. The system are strongly related to material origin and construction process. The Expression of vernacular tradition are an implicit "poetics" or explicative theory. The Traditional House of Japan is a good example of vernacular tectonics, providing an essential expression of construction potentials of material.

2. Tectonic as Culture: prioritizing building and construction, since the $19^{\text {th }}$ Century and through modern periods can be seen that the theory of tectonic 
evolve through the nature of design. According to Frampton "the poetry of constructions" is the foundation of modern Architecture and shape, structures and materials still interpretated separately. This condition brings a closer exploration of tectonics to contemporary definition in which fabrication and manufacturing are viewed as parametric systems.

3. Digital Tectonics as virtual and physical materiality. There are various different approaches of digital tectonics in the last decade: 1 . digital tectonics as virtual materiality, a virtual computational space is an accommodation of material representation. 2. Digital tectonics as physical materiality, digital tectonics was related to dynamic factors of motion, information, generation and fabrication. 3. Digital tectonics as fabricated materiality 4 . Digital Tectonics as structured materiality, digital technologies make technological possibilities more affordable 5. Digital tectonics as digital form-finding and morphogenetic processes, related to form-finding processes and in-nature 6 Digital tectonics as adaptive materiality, adaptive building required an adaptive material by system performance of material.(Oxman 2012)

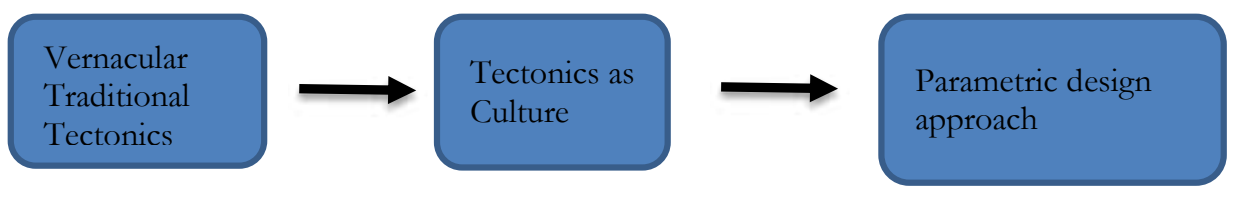

Fig.1 Scheme of Vernacular Tectonic to Informed Tectonics concept

\section{RESEARCH FRAMEWORK}

This research are proposing an alternative formation of Trowulan Bricks construction. The original intention is to involving the emerging engineering design technologies on the design stages. This Research drew on simulation based research. In General, the bricks of Trowulan paradigm will be categorized on Tectonics concept of Oxman. The traditional of bricks formation will be reinterpretated by generative software. The Bricks formation will be modelled in the Rhino modeling software and the parameters of object studies will be calculated and projected by Grasshopper plug ins. The model of objects will be simulated in Rhino software and printed in scaled models by $3 \mathrm{~d}$ printer.

\subsection{Vernacular Traditional Tectonics.}

Trowulan bricks have the same material with Terracotta crafts. Majapahit temples found also use the same material. The bricks are derived from Trowulan's distinctive red soil. The clay should be wetted before it was used for bricks process and it will be pressed until become solid. Once the soil becomes solid then it can be molded, followed by drying and burning process. This process has been known for hundreds of years. This traditional process is done repeatedly from time to time. Most of industry is home industry and the skills were taught from generation to generation. The quality of home industry bricks was not 
mathematically precise and the quality very dependently to weather condition but this kind of brick are affordable for every customers segment.

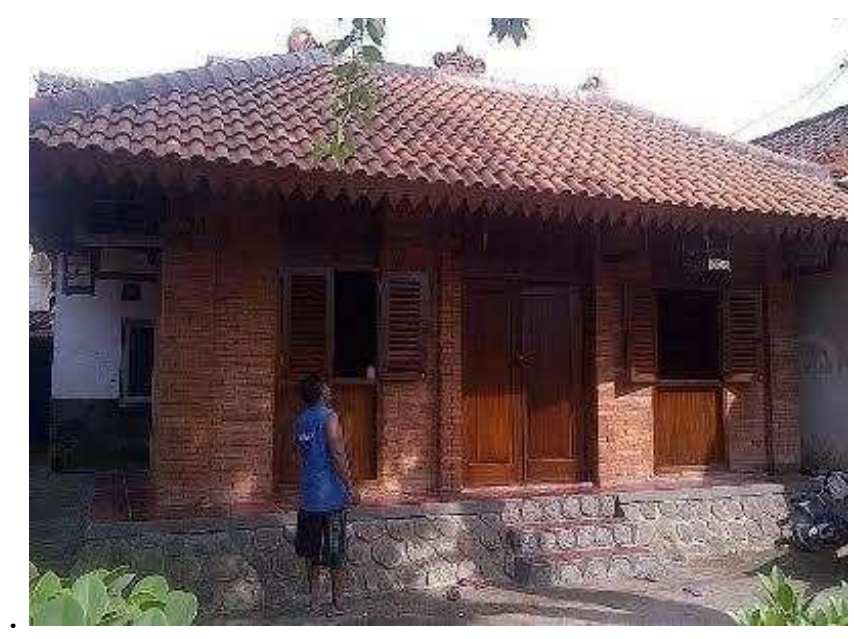

Fig.2 Traditional House of Majapahit Village in Trowulan

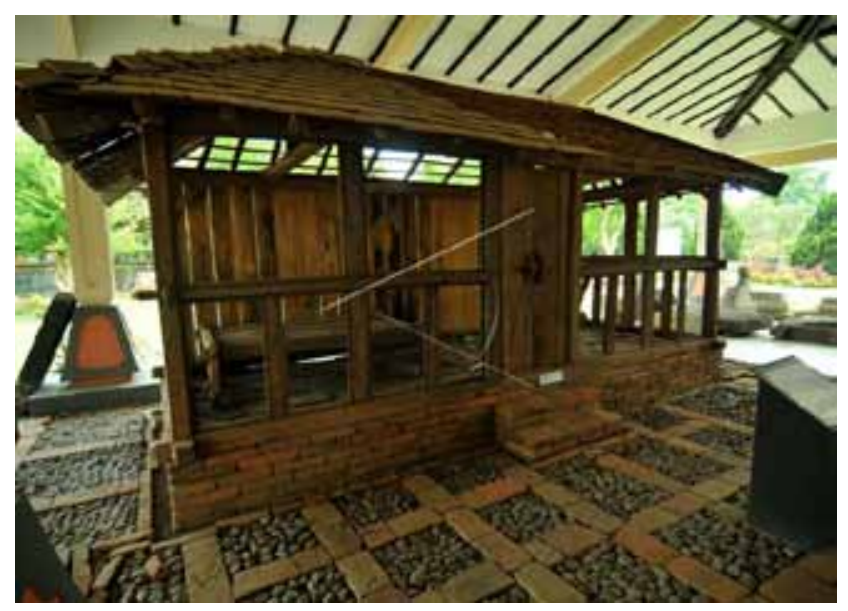

Fig.3 Traditional construction House of Majapahit Village in Trowulan

From the image of Majapahit's Village house (fig 1 and 2), it can be seen the expression of materiality and its construction system. Timber structure works as main support of roof structure and also as a frame of wall system. From this case can be viewed that the choices of materials structure will informed the construction process. Vernacular Tectonics are giving an inter-related information both structure system and constructional process. Building materials technology are involving to become one building systems. Such system more or less describes material origins and construction process. Vernacular building is a product of craft tradition such as masonry.

2.2. Tectonics as culture: prioritizing building and construction.

According Gottfried Semper (1803-1879) mentioned that tectonics is a phenomenon that describe the use of different materials in architecture as a cultural phenomenon. He was reffering a review of the physical relationship order of structure and material. (Oxman 2012) 


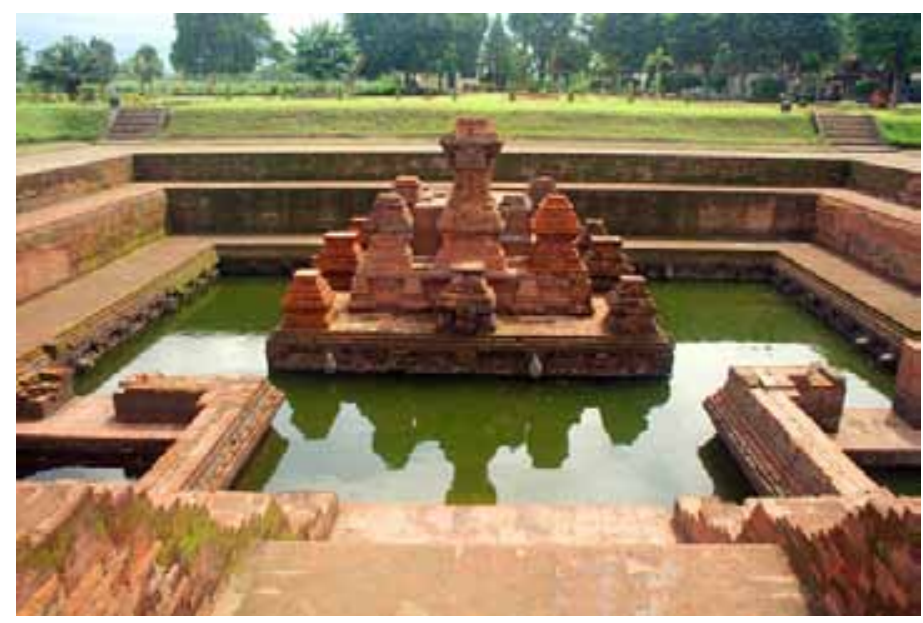

Fig.4 Candi Tikus built in $15^{\text {th }}$ century

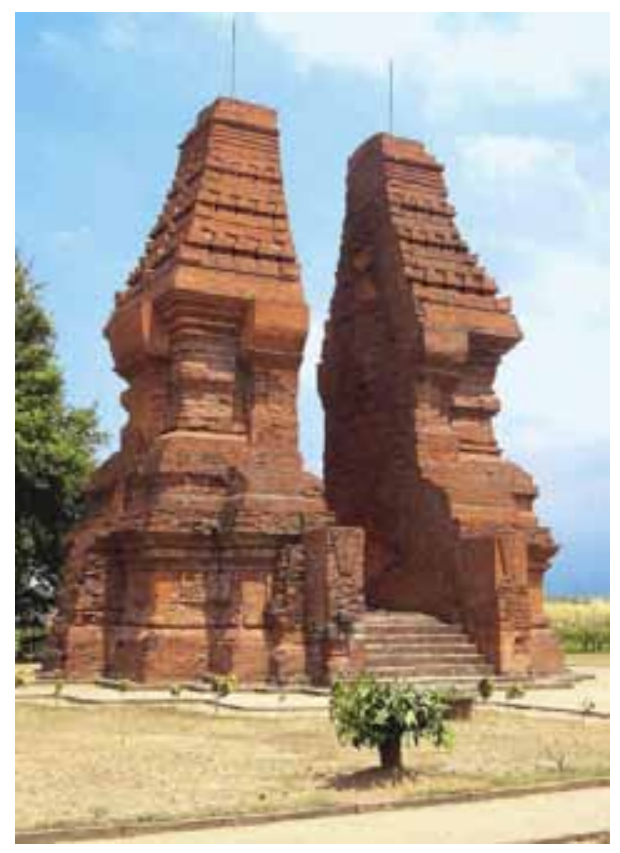

Fig. 5 Wringin Lawang built in $15^{\text {th }}$ century

Based on Frampton (1995), the interpretation of structural form development in architectural context is more than visual, space experience, content of tectonics. From the image of Candi Tikus and Wringin Sewu can seen that formation of bricks or brick layering become an essential part of its form. The Temple of Majapahit describes the "poetic of construction" that mentioned by Frampton. Nowadays, there are some different bricks dimension that commonly used in

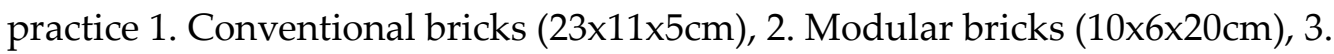
Norman Bricks (10x6x30cm), 4. Engineered Bricks (10x8x20cm), 5. Norwegian

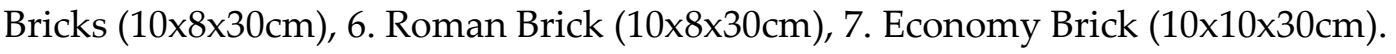
In Indonesia there are 3 general types of Bricks 1. Handmade Bricks is the bricks that made manually, very affordable and the quality are strongly depend on weather condition. 2. Pressed Bricks process was made in factory with a modern machine. Bricks was burned in the oven in a high temperature (1000 celcius) and 
it was cooled for 48-72 hours. Pressed Bricks have a better quality. 3. Tiles Bricks is a type of brick that being used for finishing or decoration purposes. There are also 4 different way of bond of bricks 1 . Stretcher Bond or known as Running Bond is the longer narrow face of the bricks. It was a simple repeating pattern. 2. Header or heading bone is the short square face of the bricks. It was used for construction of walls. 3. English Bond is a combination between stretcher and header bond. 4 . Flemish Bond, also known as Dutch bond, is created by laying alternate headers and stretchers in a single course. (Akmal 2010)

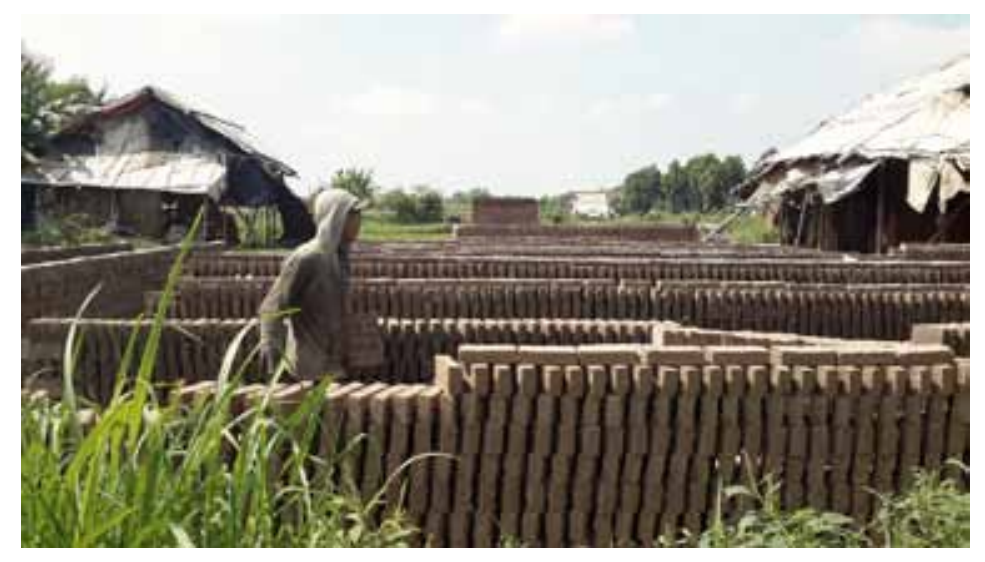

Fig.6 Traditional bricks industry

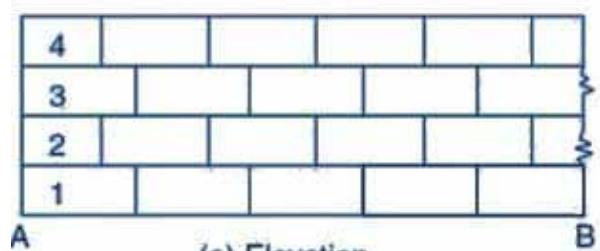

(a) Elevation

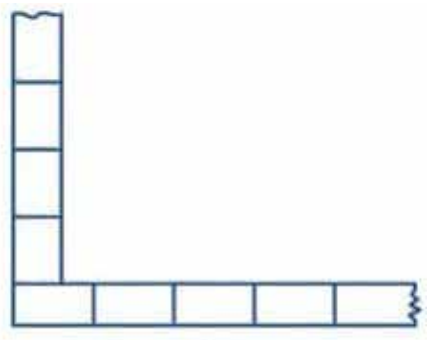

$1,3,5$... Courses

(b) Plan

Fig.7 Stretcher Bond (the constructor.org)

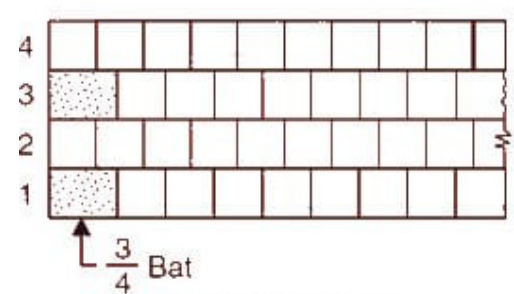

(a) Elevation

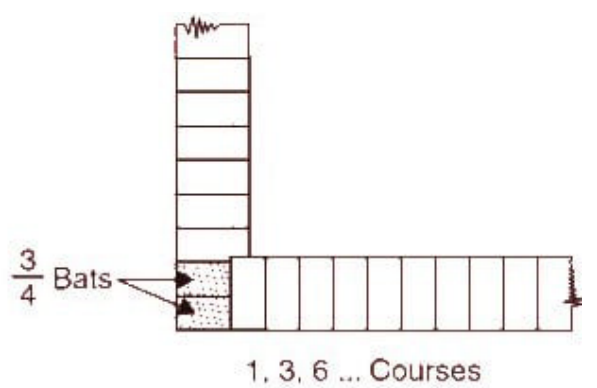

(b) Plan

Fig.8 Header Bond (the constructor.org) 

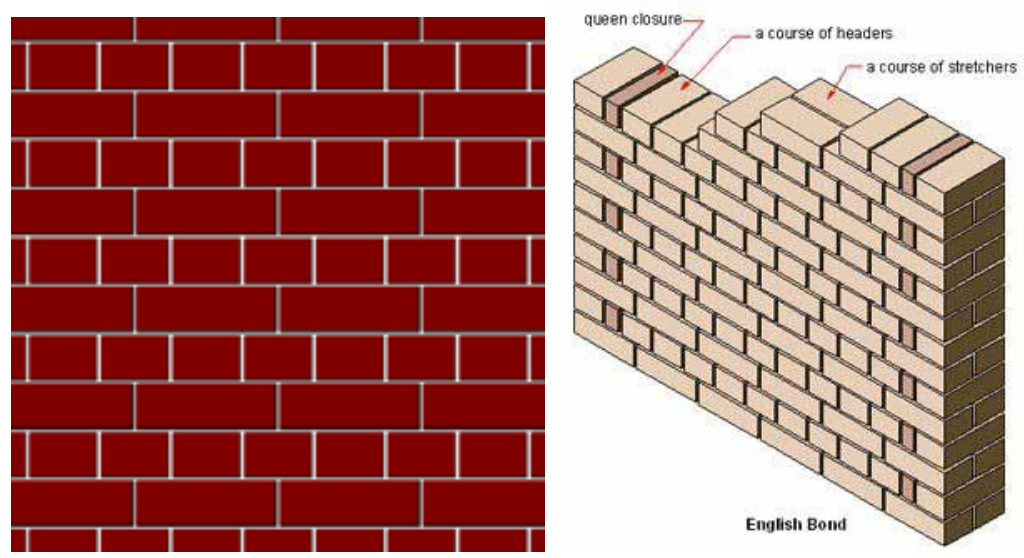

Fig.9 English Bond (the constructor.org)

Masonry Wall in Indonesia still labor intensive and manualy done by construction workers. Masonry wall should be supported by column on every 12 square meters and bricks material should placed in a dry place. Every level of bricks should measured by waterpass and weighted by "benangan". After the bricks was installed, it should be cleaned by sand paper and roskram. From this explanation can be seen that bricks industry especially in Trowulan haven't touch much by technology of design nor engineering process.

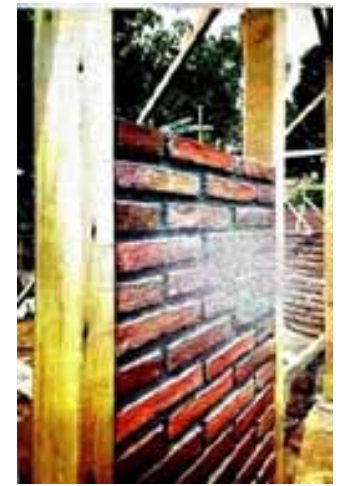

Fig 10. Masonry wall and support

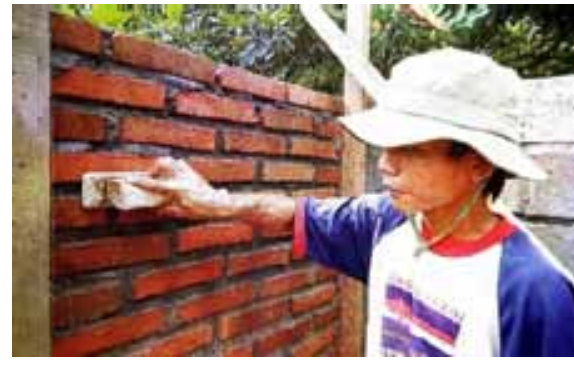

Fig 11. Construction process done manually

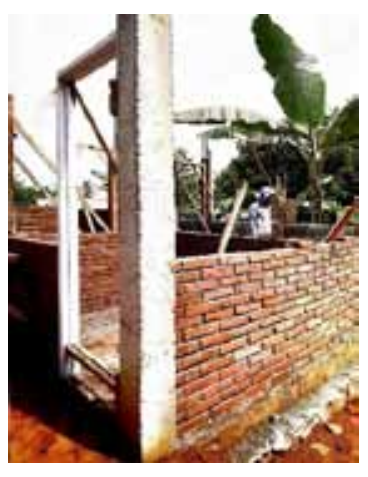

Fig 12.

Construction

\subsection{Parametric design approach}

From the explanation above can be seen that bricks still separated from design process. Parametric design approach are challenge orthodox working methods of design. Designers and engineer should involved at the early stages at generative stage. There are two different way of approaching the design, it is the top down and bottom up as a trial and error process. Top down is a stepwise approach, started from general pictures and broken down into a sub element. Designwise, some steps cannot be too specified for detailed system to fit in. Bottom up is a approach where the system collected together by individual elements. This system will be connected together until the top system can be defined clearly. 


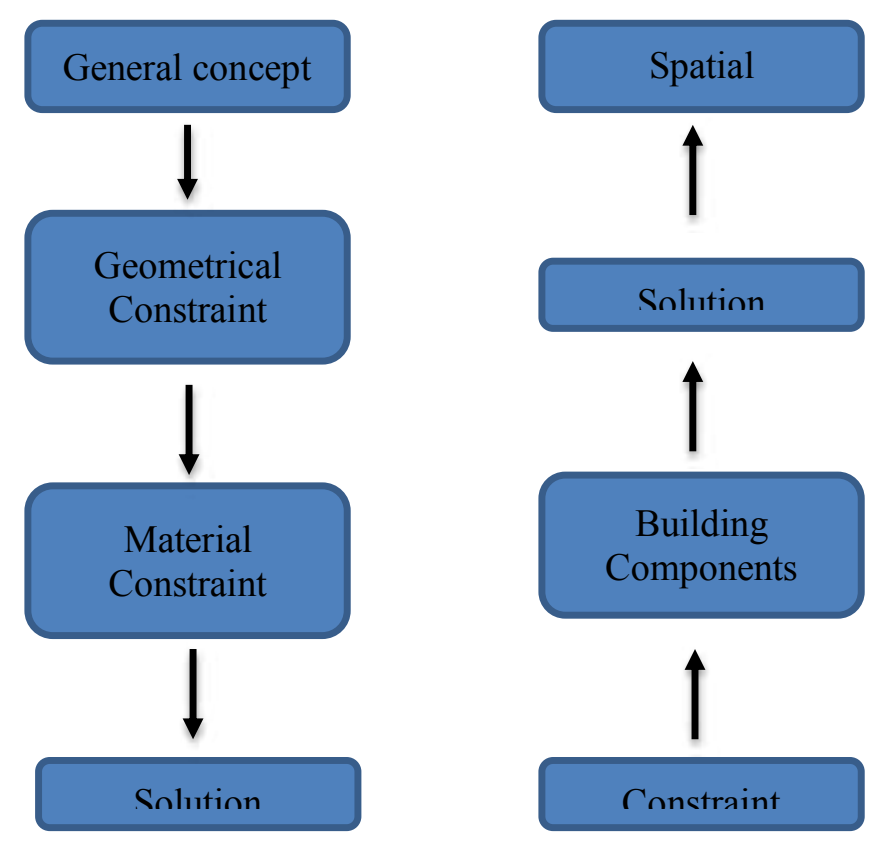

Fig 13. Design Approach Scheme

The combination of both scheme can be usefull for complex design. It gives a better vision on what the desired design should look like. The explanation will start from spatial concept

\section{GENERAL CONCEPT}

Bricks has many times used for contemporary architectures materials, because the quality and the cost are widely range. This research focuses on Bricks that made by Trowulan Villagers. The production are very traditional and labour intensive because the molding process and burning process are done mostly manual. The advantage of bricks from Trowulan is longlife lasting, weatherproof, fireproof, waterproof, special skills are not required, have a relative small dimension-easy for transport, special adhesive are not required and affordable. The disadvantage of handmade Bricks are construction process is long, a strong gap temperature will decrease bricks quality, Bricks are heavy, neat and precise construction quality is hard to achieve. The formation of bricks are commonly build along Cartesian Coordinate system. Mathematically the location of objects are specified by each point in a pair of numerical coordinates. The coordinate described as a position of perpendicular projection of points.

\section{GEOMETRICAL CONSTRAINT}

In 3D modeling software such Rhinoceros, Cartesian Coordinate system can be evolved into UV mapping. UV is a different name of XYZ coordinates because its already used for model space. UV texturing makes 3D object to be painted or applied with material texture or color. The UV mapping process involves applying pixels in the image to surface mappings on the polygon. This process normally done "programmatically" by pasting material onto triangular surface 


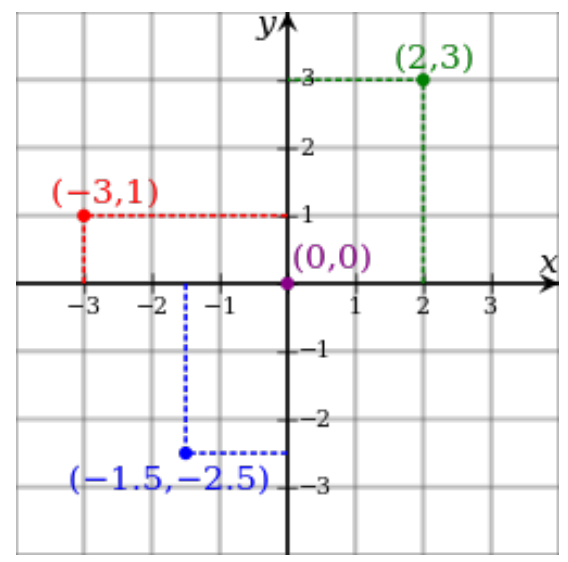

Fig 14. Cartesian Coordinate

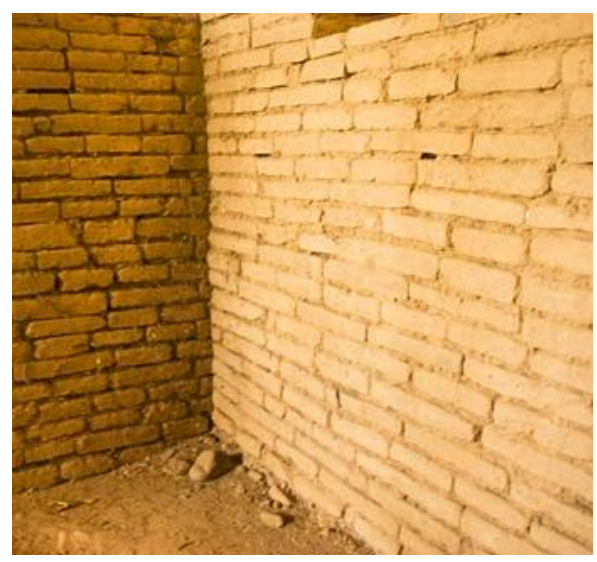

Fig 15. Wall of Candi Kedaton

(Mullen 2009). UV only maps material onto texture space rather than geometrical space of objects. Parametric Design approach using the principles of UV Mapping to apply geometry onto surface(Murdock 2008). From figure (fig.14) below can be seen a schematic surface that commonly (left) and uncommonly (right) used for masonry wall. The Loft was generated by grasshopper (gh) definition, it was divide in some layers (based on user needs) by contouring method. Contouring is a techniques that shaping a surface in order to create three dimensional relief by removing successive layers of material. (Iwamoto 2010).
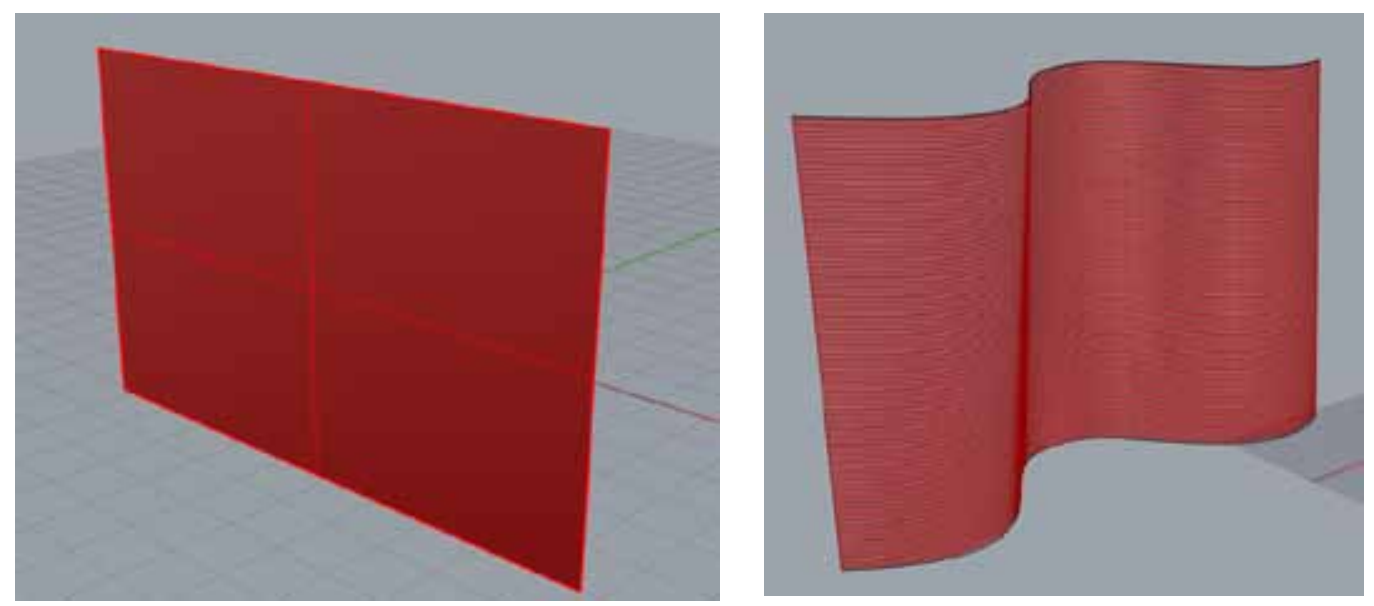

Fig 16. Flat Surface and dynamic Loft

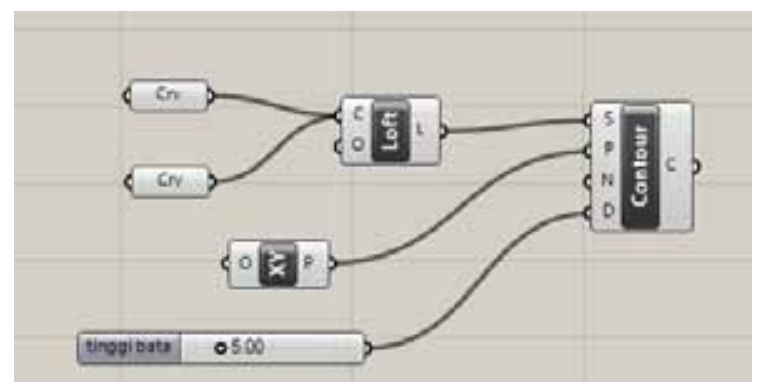

Fig 17. The definition of Loft made by grasshopper plugins (for Rhino)

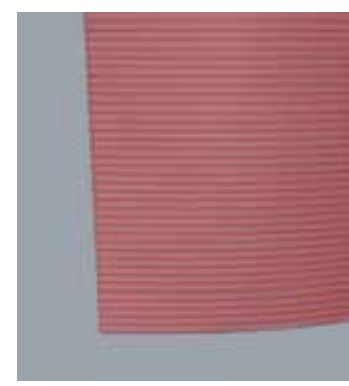

Fig 18. Loft divided base on Bricks Height 


\section{MATERIAL CONSTRAINT}

The type of brick that being used for this research is Handmade bricks because of its advantages and disadvantages. Handmade Bricks is the bricks that made manually by Trowulan Villagers, very affordable and the quality are strongly depend on weather condition. Conventional bricks $(23 \times 11 \times 5 \mathrm{~cm})$ is a sample of objects that will be generated by parametric design model. Stretcher bond also a sample masonry bond for this model because its commonly used in Indonesia.
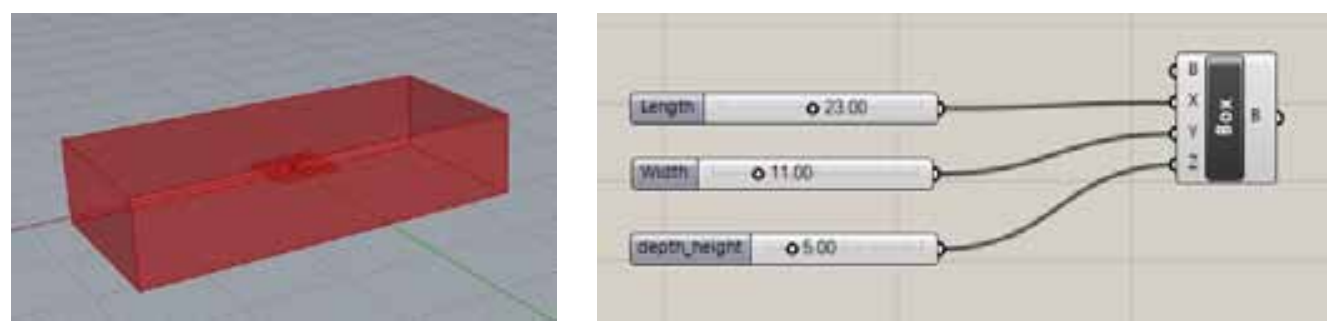

Fig 19. Bricks based on grasshopper definition
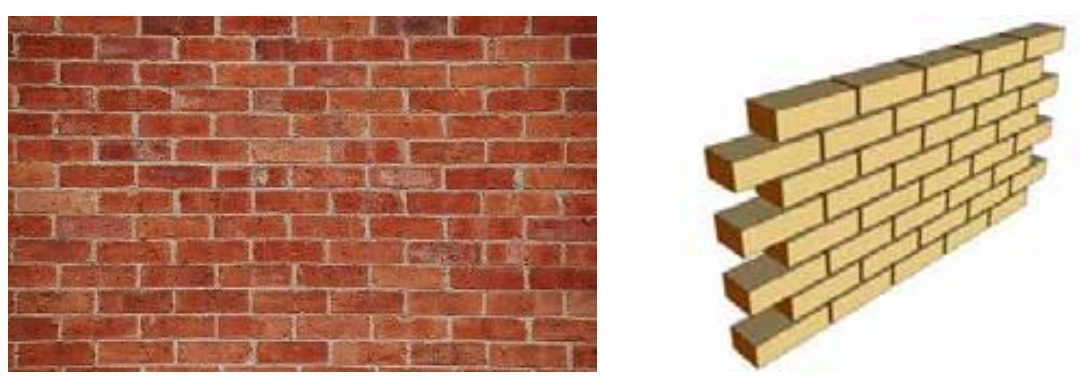

Fig 20. Stretcher Bond

After the loft/surface being divided into contour lines, the bricks placed along the curve lines. Planes were spread along the curve as a base for bricks model. Every curve lines from surface will re-mapping the surface in 3 dimensional objects with bricks.
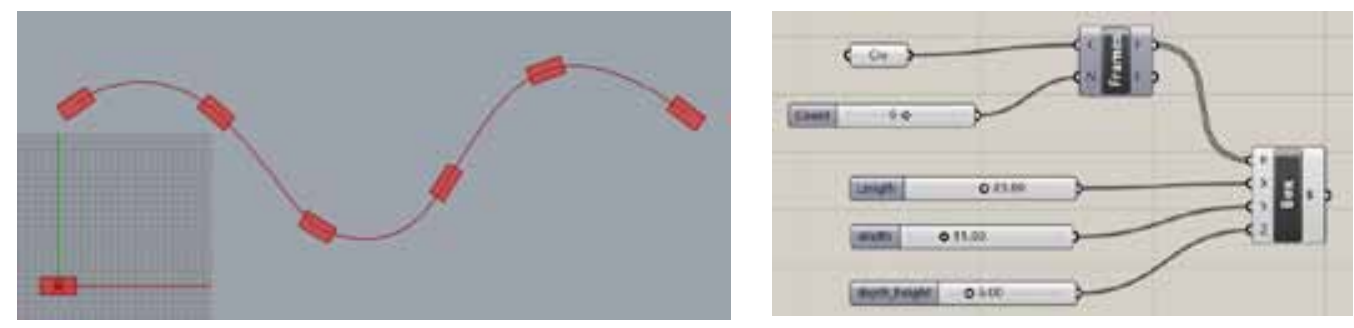

Fig 21. Dividing contour lines 


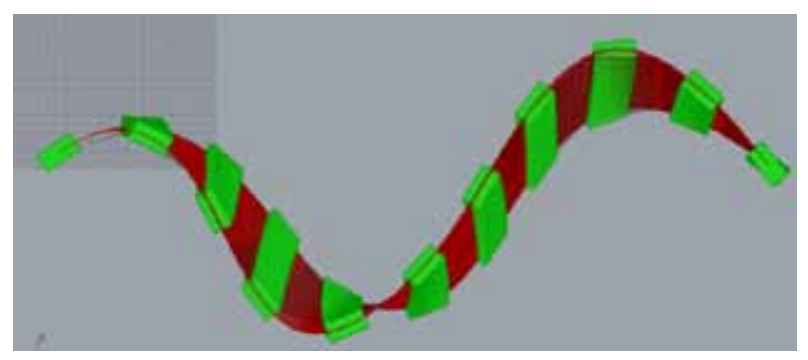

Fig 22. The result from definition of box,loft and contour

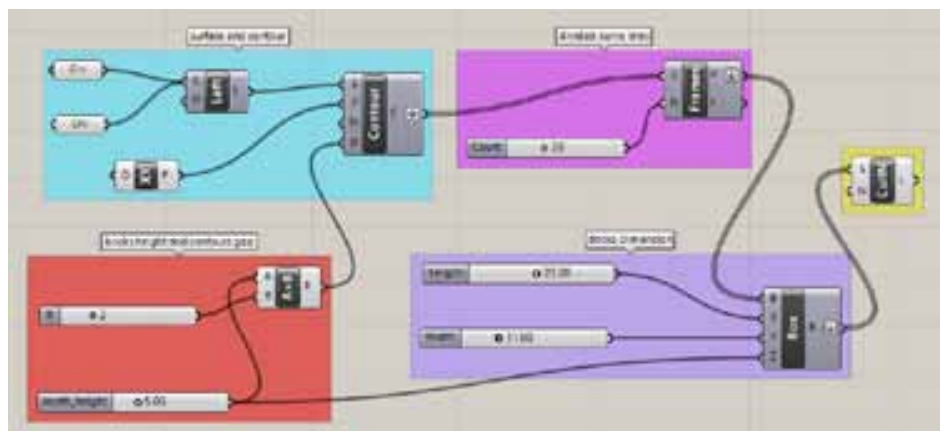

Fig 23. Compiled definition

From the compiled definition can be seen that the position of bricks are not placed properly. The number slider of each definition is a parameter to shape the object through visual definition. User can slide each parameter to achieve desired form. Parametric design process consist of the following components 1. Design Schema 2. A means creating variations 3. A means selecting desirable outcomes. (Krish 2011)

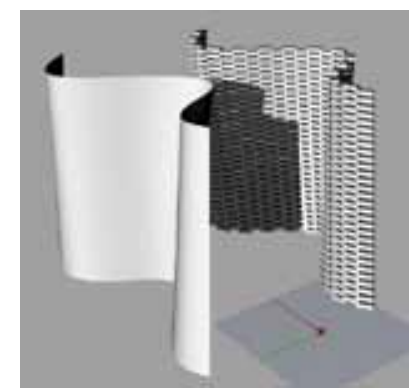

Fig 24. From Loft to bricks

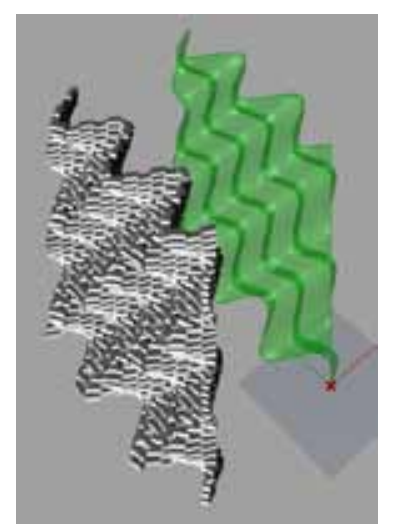

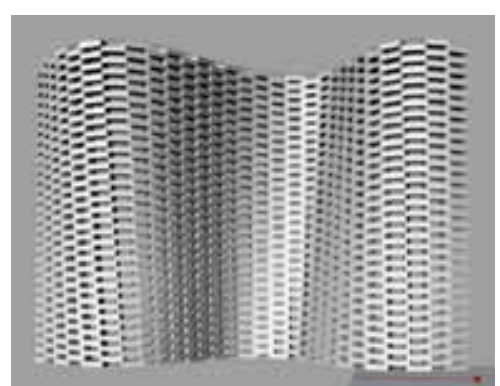

Fig 25. Finished

Fig 26. Alternatives Formation of Bricks from 


\section{SOLUTION}

From the explanation above can be seen that the core definition can be plugged into different kind of lofts. The building process for construction may depend upon reinterpretation of specific tectonic properties. Since the Trowulan village have a highly skilled workers, specific design can easily implemented. The knowledge of structures, materials, construction method is a key factor in creation of parametric design. The next phase of this process is to build a scale model. Scale models are printed with $3 \mathrm{~d}$ printer. $3 \mathrm{D}$ printer works based on contouring procedure, from printing process can be seen possibilities to build it. Parametric design approach and material $=$ based design fabrication are now integrated in one singleline process. (fig.27)

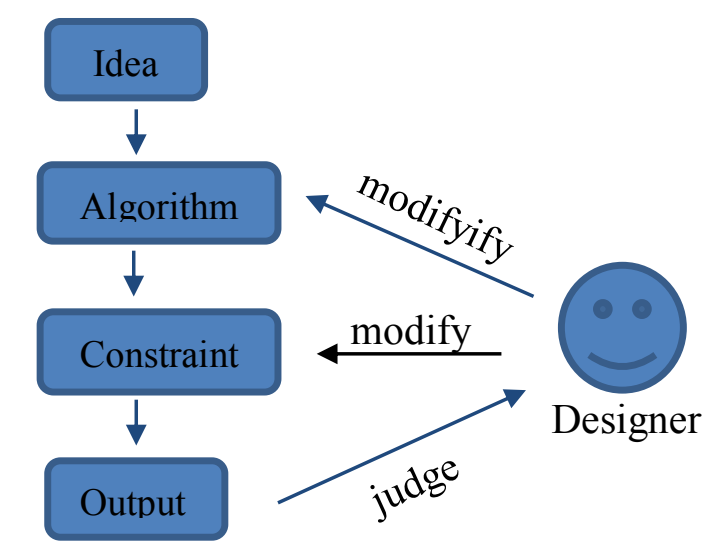

Fig 27. Scheme of parametric design approach (Krish 2011)
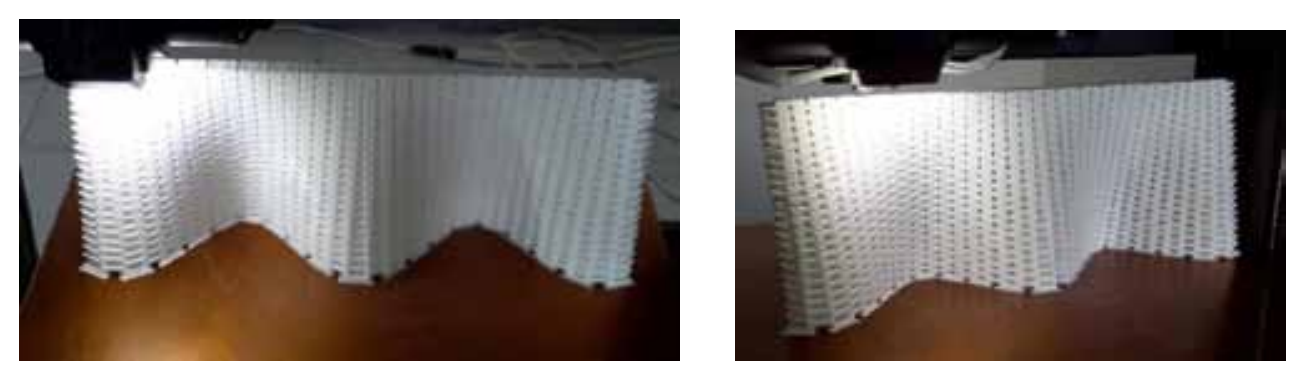

Fig 28. Scale Model

\section{CONCLUSION}

The emerging technologies of fabrication and design software has been seen as a possibilities to find alternatives creation of manual craft. Within the framework of parametric design approach, the formation of bricks layering can be described as a process that enhance the integration between tectonic properties of construction rules (masonry bond) within the logic and the rationale of fabrication technologies. The knowledge of tectonics and parametric design are become the main concept to bridge the relation between tradition and contemporary design approach.Parametric design has been introduced as a basis to find an alternative ways to produce traditional craft. 


\section{REFERENCES}

Akmal, Imelda. 2010. Seri Rumah Ide : Bata. 1st ed. ed. Fialita F. jakarta: PT Gramedia PustakaUtama. https://www.getscoop.com/id/buku/seri-rumah-ide-bata-kuatawet-indah-eksotis.

Iwamoto, Lisa. 2010. Architecture briefs. Digital Fabrications :architectural and Material Techniques. http://www.papress.com/html/ book.details.page. tpl?cart=125777262860796\& isbn=9781568987903.

Krish, Sivam. 2011. "A Practical Generative Design Method." CAD Computer Aided Design 43(1): 88-100. http://dx.doi.org/10.1016/j.cad.2010.09.009.

Mullen, T. 2009. MasteringBlender. 1st ed. Indiana: Wiley Publishing. http://as.wiley. com/WileyCDA/WileyTitle/productCd-1118275403.html.

Murdock, K L. 2008. 3DS Max 2009 Bible. 1st ed. Indiana: Wiley Publishing.

Oxman, Rivka. 2012. "Informed Tectonics in Material-Based Design." Design Studies 33(5): 427-55. http://dx.doi.org/10.1016/j.destud.2012.05.005.

Utomo, Tri Noviyanto P et al. "Identifikasi Potensi Pengembangan Produk Untuk Arsitektur Interior Berbasis Karakteristik Material Seni Kerajinan Trowulan." : 5-21. http://journal.uc.ac.id/index.php/AKSEN/article/view/230/213. 